\title{
Disseminated HIV-Associated Kaposi's Sarcoma With High CD4 Cell Count And Low Viral Load
}

\author{
Diana Pereira Anjos, Ana João Sá, André Paupério, Mari Mesquita \\ Serviço de Medicina Interna. Centro Hospitalar Tâmega e Sousa (CHTS)
}

Keywords: kaposi's sarcoma, HIV, CD4

\begin{abstract}
Kaposi's sarcoma is considered an acquired immunodeficiency syndrome-defining illness and is caused by human herpesvirus 8 . It has been associated with patients infected with human immunodeficiency virus (HIV) who have CD4 T lymphocytes $<200$ cells/uL and high viral loads. We report a case of a 23-year old woman infected with HIV-1 and receiving antiretroviral treatment since diagnosis, with high CD4 cell count and low viral load that presented with disseminated Kaposi's sarcoma. Clinicians should be aware of the occurrence of Kaposi's sarcoma despite robust CD4 cell counts.
\end{abstract}

\section{INTRODUCTION}

As an acquired immunodeficiency syndrome (AIDS)-defining cancer, most Kaposi's sarcoma (KS) cases have traditionally occurred at low CD4 cell count (<200 cells/uL). With the widespread use of potent antiretroviral therapy (ART), the spectrum of this neoplasia has dramatically changed. There have been some reports, in recent years, pointing to the increasing number of KS cases in patients with a higher CD4 cell count. This refers to both naïve and ART-treated patients. ${ }^{1}$

\section{CASE REPORT}

A 23-year-old woman, with a history of intravenous drug use, was diagnosed with HIV-1 infection in December 2014 with a CD4 cell count of 424/uL (nadir value) and a viral load of 52297 copies $/ \mathrm{mL}$ (4.72 log). On diagnosis, she started on ART consisting of ritonavir $110 \mathrm{mg}$ id, darunavir $800 \mathrm{mg}$ id, abacavir $600 \mathrm{mg}$ id and lamivudine $300 \mathrm{mg}$ id. In February 2015, she complained of an acute onset of odynophagia without other symptoms. The physical examination showed multiple, well-defined, non-scaly, discrete, violaceous to hyperpigmented plaques of variable size over her buttock and thighs; left amygdalin hypertrophy with multiple painless violaceous macules and left cervical adenopathic conglomerate. Laboratory results presented iron-deficiency anemia with otherwise normal blood count, C-reactive protein, liver and kidney function. The viral load was 712 copies/mL $(2.85 \mathrm{log}$ ) and her CD4 cell count measured 595/ul (23.4\%). A biopsy was performed in her left amygdala and cervical adenopathy. The histology revealed a tumor consisting of spindle cells with some irregular vessel lumina formation, as well as plasma cells and erythrocyte extravasates in the tumoral stroma yielding the diagnosis of KS. Human herpesvirus 8 (HHV8) immunochemistry staining was positive in the spindle cells thus confirming the histological diagnosis. To screen for possible further organ involvement, the patient underwent: thoracoabdominal axial tomography, which demonstrated bilateral adenopathy in the internal jugular, axillar, inguinal and external iliac lymph node chains; bronchoscopy revealed a nasopharyngeal polypoid lesion (Figure 1) and violaceous macules in the aryepiglottic fold, left vallecula and infraglottic cavity; esophagogastroduodenoscopy exhibited vinous and friable subepithelial lesions (Figure 2). With the diagnosis of disseminated Kaposi's sarcoma, the patient continued the current antiretroviral therapy and started intravenous liposomal doxorubicin at a dose of $50 \mathrm{mg} / \mathrm{m} 2$ every two weeks. After the fourth cycle, and with significant clinical improvement, the patient quit the treatment plan and returned to heroin use.

\section{DISCUSSION}

Since 1872, when dermatologist Moritz Kaposi described a new tumor in his article "Idiopathic multiple pigmented sarcoma of the skin", KS has been widely diagnosed all over the world. KS is a multifocal angioproliferative neoplasm affecting the skin, lymph nodes or viscera. Its prevalence varies depending on sex, age and region, and it is classified into four forms epidemiologically: "classic" KS occurs in elderly men of Eastern European or Mediterranean ancestry; "endemic" KS occurs in equatorial Africa, and affected children may present with disseminated lymphadenopathy; "iatrogenic" KS is associated with immunosuppressive therapy; and "epidemic" or HIV-associated KS has long been considered an AIDS-defining illness, and is a cause of significant morbidity and mortality. These four forms are indistinguishable histologically.

Human herpesvirus 8, also referred to as KS-associated herpesvirus, was identified in 1994 as the etiological agent of $\mathrm{KS} .{ }^{2} \mathrm{HHV} 8$ is a gamma herpes virus that infects endothelial cells and/or haemopoietic progenitors, leading to alterations in metabolism and gene expression, and ultimately resulting in the development of KS. ${ }^{3}$ Replication of HHV8 involves both latent and lytic phases. In immunocompetent hosts, this infection may be lifelong and asymptomatic. Immune surveillance of HHV8- infected cells is thought to be mediated mainly by $T$ cells, and T-cell responses against both lytic and latent HHV8 proteins have been detected. ${ }^{4}$ mpaired T-cell function or lack of HHV8-specific cytotoxic lymphocyte cells ${ }^{5}$ may lead to uncontrolled proliferation of HHV8-transformed cells. Similar to other herpesviruses, it is transmitted through close person-to-person contact and establishes persistent infection.

The introduction of ART seems to have altered the disease course. ${ }^{6}$ It has been shown that both protease inhibitor-based and non-protease inhibitor-based regimens have antiangiogenic effects, and patients with KS who take ART have a lower risk of dying compared with patients from the pre-ART era, despite 
similar CD4 counts and HIV viral loads. ${ }^{7}$ Limited local disease may be treated with a variety of therapies depending on size and location including cryotherapy, laser therapy, radiation, and intralesional chemotherapy (eg, vinblastine). Systemic therapies for disseminated disease include two liposomal anthracyclines (doxorubicin and daunorubicin) and the taxane paclitaxel.

KS, similarly to other AIDS-defining diseases such as non-Hodgkin lymphoma and cervical carcinoma, has been related to a low CD4 count and a high HIV viral load. The development of KS in patients infected with HIV with high CD4 cell count is rare, although, theoretically, KS may occur at any stage of HIV infection. The occurrence of KS in a patient started on ART is even more remarkable because initiation of ART at a very early stage of infection is associated with preserved immune function. ${ }^{5}$ Mocroft et al. made an assumption that immune reconstitution is not complete until the level of 500 cells/ul and only after the CD4 count reaches $\geq 750$ cells, we can talk about protection against KS. ${ }^{8}$ The high level of patient's viraemia can also be a contributing factor in the rapid progression of the disease. Nonetheless, this factor is not clearly evaluated in the literature. What triggers the development of KS in patients under successful ART with formally normal immune function is still unknown. ${ }^{9}$

This article reminds us that although the KS rates have declined during the ART era and lower CD4 counts remain a significant risk factor, a greater proportion of KS cases are now occurring at higher CD4 counts. We emphasize the importance of keeping KS in our diagnostic hypothesis in order not to miss this potentially devastating disease.

\section{REFERENCES}

1. Uldrick TS, Whitby D. Update on KSHV epidemiology, Kaposi sarcoma pathogenesis, and treatment of Kaposi sarcoma. Cancer Lett 2011; 305: 150-62.

2. Chang Y, Cesarman E, Pessin MS, Lee F, Culpepper J, Knowles DM et. al. Identification of herpesvirus-like DNA sequences in AIDS-associated Kaposi's sarcoma. Science 1994; 266:1865-9.

3. Hong YK, Foreman K, Shin JW, Hirakawa S, Curry CL, Sage DR et al. Lymphatic reprogramming of blood vascular endothelium by Kaposi sarcoma-associated herpesvirus. Nat Genet 2004; 36:683-5.

4. Bihl F, Narayan M, Chisholm JV, Henry LM, Suscovish TJ, Brown EE et al. Lytic and latent antigens of the human gammaherpes viruses Kaposi's sarcoma-associated herpesvirus and Epstein-Barr virus induce T-cell responses with similar functional properties and memory phenotypes. J Virol 2007; 81:4904-8.

5. Lambert M, Gannage M, Karras A, Abel M, Legendre C, Kerob D et al. Differences in the frequency and function of HHV8-specific CD8 T cells between asymptomatic HHV8 infection and Kaposi sarcoma. Blood 2006; 108: 3871-80.

6. Bower M, Collins S, Cottrill C, Cwynarski K, Montoto S, Nelson M et al. British HIV Association guidelines for HIV-associated malignancies 2008. HIV Med 2008; 9:336-88.

7. Gallafent JH, Buskin SE, De Turk PB, Aboulafia DM. Profile of patients with Kaposi's sarcoma in the era of highly active antiretroviral therapy. J Clin Oncol 2005; 23: 1253-60.

8. Mocroft A, Furrer HJ, Miro JM, Reiss P, Mussini C, Kirk 0 et al., The incidence of AIDS defining illnesses at a current CD4 count $\geq 200$ cells/ $\mu \mathrm{L}$ in the post-combination antiretroviral therapy era. Clin. Infect. Dis. 57 (2013) 1038-1047..

9. Maurer T, Ponte M, Leslie K. HIV-associated Kaposi's sarcoma with a high CD4 count and a low viral load. N Engl J Med 2007; 357: 1352-3.

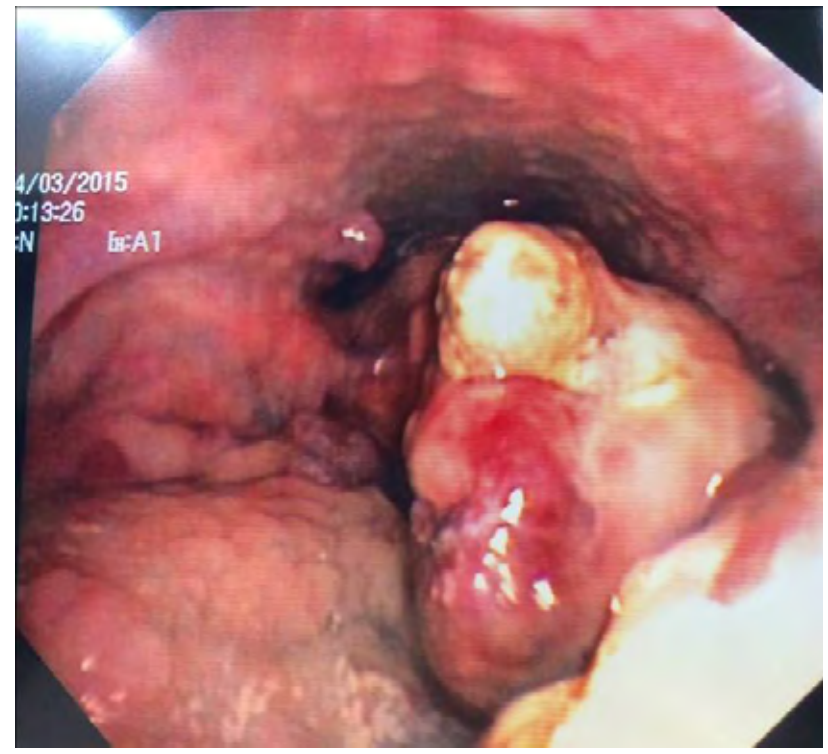

Figure 2. Vinous subepithelial lesions in the gastric mucosa

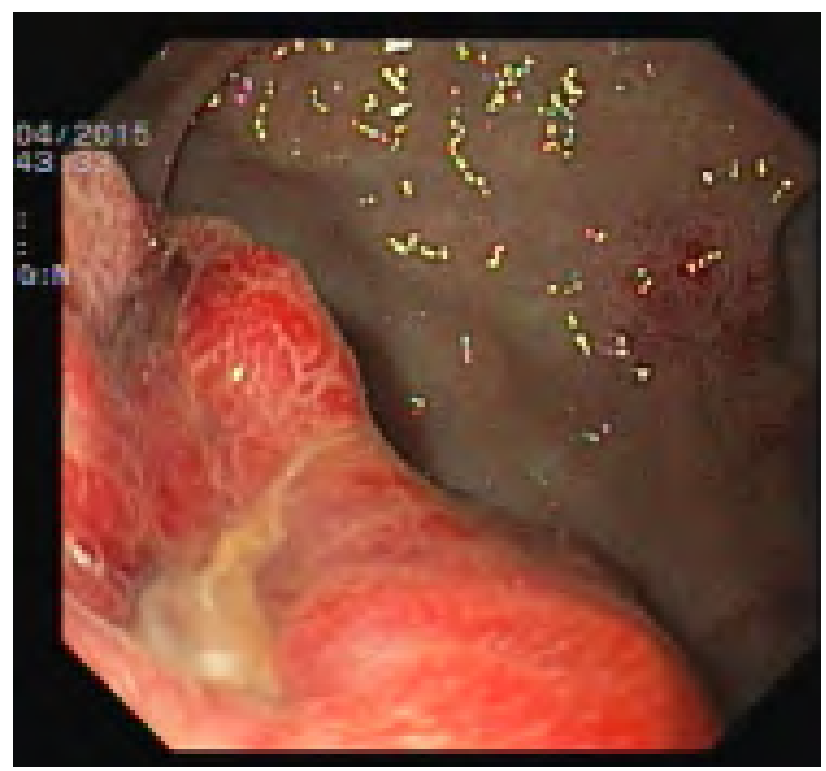

